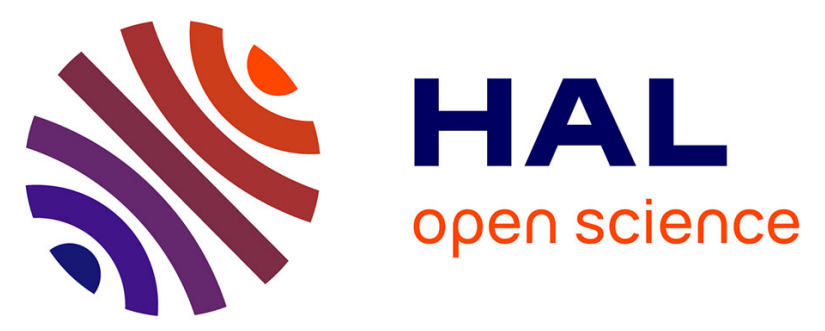

\title{
Measuring the Impact of ICTs on the Quality of Life of Ageing People with Mild Dementia
}

\author{
Mounir Mokhtari, Romain Endelin, Hamdi Aloulou, Thibaut Tiberghien
}

\section{To cite this version:}

Mounir Mokhtari, Romain Endelin, Hamdi Aloulou, Thibaut Tiberghien. Measuring the Impact of ICTs on the Quality of Life of Ageing People with Mild Dementia. ICOST: International Conference on Smart homes and Health Telematics, Jun 2014, Denver, CO, United States. pp.103-109, 10.1007/9783-319-14424-5_11. hal-01098457v2

\section{HAL Id: hal-01098457 \\ https://hal-lirmm.ccsd.cnrs.fr/hal-01098457v2}

Submitted on 24 May 2019

HAL is a multi-disciplinary open access archive for the deposit and dissemination of scientific research documents, whether they are published or not. The documents may come from teaching and research institutions in France or abroad, or from public or private research centers.
L'archive ouverte pluridisciplinaire $\mathbf{H A L}$, est destinée au dépôt et à la diffusion de documents scientifiques de niveau recherche, publiés ou non, émanant des établissements d'enseignement et de recherche français ou étrangers, des laboratoires publics ou privés. 


\title{
Measuring the Impact of ICTs on the Quality of Life of Ageing People with Mild Dementia
}

\author{
Mounir Mokhtari ${ }^{1,2,3}$, Romain Endelin ${ }^{1,3}$, Hamdi Aloulou ${ }^{1,3}$, Thibaut Tiberghien ${ }^{1,2}$ \\ ${ }^{1}$ Institut Mines Telecom, ${ }^{2}$ CNRS IPAL (UMI 2955), ${ }^{3}$ CNRS LIRMM(UMR 5506) \\ \{Mounir.Mokhtari, Romain.Endelin, Hamdi. Aloulou, Thibaut.Tiberghien\}@Mines- \\ Telecom.fr
}

\begin{abstract}
The growing of ageing population worldwide and the need to focus research efforts on a specific target group motivate our research to focus on frail ageing people with chronic disease and physical/cognitive deficiencies. The primary goal is to enable the frail and dependant persons, through reliable assistive technologies, to maximize their physical and mental functions, and to continue to engage them in social networks, so that he can continue to lead an independent and purposeful life. Our target is to analyze the users' habits at home through an extensive survey performed in France recently, and to design a suitable assistive system, which is mainly composed of devices available in the market. This research activity led to the deployment of a simplified hardware infrastructure (gateway, sensors, actuators) in the home of end-users with a limited number of wireless sensors, and to the outsourcing of all the software for data analysis in a framework running on a distant server. The research focuses on the quality of life of ageing people having cognitive and functional limitations, and on recent achievements realised in France and Singapore through several European and national projects, and through Quality of Life Chair (QoL) directed by Mounir Mokhtari and supported by two major health insurance companies in France, namely la Mutuelle Generale and REUNICA.
\end{abstract}

Keywords: Ageing people, Ambient Assisted Living (AAL), Activities of Daily Living (ADL).

\section{Introduction}

Today, providing assistive services for frail and dependant people could be done following two ways: the first option consists in looking for a reliable industrial solution to be deployed in the user's living space, which may not fit exactly with the users' specific requirements and usually imposes to modify extensively the living environment itself. The second option is to design a specific application, which meets exactly the needs of the end-users, but developers will be confronted with a wide spread of technologies and APIs which impose a huge amount of human-efforts and associated cost. This second option may require a long time (several years) to build a reliable running prototype. Consequently, in both options, the development cost is high, and this is also the reason why most smart home projects are still at a laboratory 
prototype level worldwide [1]. There are efforts trying to transfer these prototypes into homes or hospitals [2], but migrating systems from a well controlled research lab environment into a much more complex real-world environment introduces tremendous challenges in terms of correctness, reliability and fault-tolerance of the system.

Ageing is a highly individualized, irreversible and inevitable process by which a person becomes more vulnerable and dependent on others [3]. It proceeds at different rates and within different functions depending on people. Changes, that can occur in cognitive, physiological and social conditions, are not necessarily related to a disease since they are, in a certain magnitude, a normal part of the ageing process.

Cognitive changes related to normal ageing span across several aspects of the mind [4]. Sensory memory is the ability for each of the five senses to hold a large amount of sensory information for a very short period of time, and is independent of the attention to the stimulus. It suffers no major influence of ageing. Short term memory is a 20 to 30 seconds memory used to hold information for processing. It is a working memory that can hold 7 elements for direct manipulation. It is highly involved in Activities of Daily Living (ADL) as it enables multi-tasking and manipulation of information. The capacity to hold 7 elements is not affected by age, but the manipulation of this memory becomes difficult as elders have a limited capacity to divide their attention between two related tasks or inhibit unimportant information. Long term memory is a series of memory modules each responsible for holding different sorts of information. It is subject to three mechanisms (encoding, storage, retrieval) that are not affected by age in the same way. Encoding is usually subject to a less spontaneous organization of information, so elders might need support on this.

Conducting a survey that involves aged people and their associated caregivers will help to understand the needs of this portion of the society and to provide solutions that Respond to their requirements. Our ultimate goal is to maintain the quality of life of aged people in their own home as long as possible by the integration of ICTs in an acceptable way for both the end-users and the stakeholders [5]. This means that economical and social impacts are key issues in our approach.

\section{Methods}

To properly define and address this issue, our methodology consisted on performing 2 parallel activities, in one hand a survey investigating the need of 123 frail aged people living in their own homes, and on the other hand designing and developing a suitable system for the provision of assistive services. 


\subsection{Survey - The lifestyle of the elders}

In order to observe the lifestyle of the elders within their home, we have sent a questionnaire to elderly people, in collaboration with a national association of retired people $^{1}$. The same questions have been asked to both the elders and their family caregivers, so that we can observe the bias in their perception. We have gathered 246 questionnaires, making up a total of 35,178 questions answered. After investigating the population of the elders and the caregivers, this survey gives insights on the elders' activities at home and outdoor, as well as the healthcare services they receive. From this survey, we aim to determine the most critical needs of elderly people in their daily lives.

In the Fig. 1 below, we observe the causes of insecurity, as felt by the elders as well as their caregivers. We observe that, many of the elders have developed a fear of other people (20\%). But only $14 \%$ are concerned by their own condition and the risk of having an accident. On the other hand, from the caregivers' point of view, 23\% have fear because the house is not suited for the patient (e.g. presence of stairs). In total, $50 \%$ are worried for the health of the patient, dispatched between an unsafe house, cognitive problems, autonomy problem, and the risk of accident.

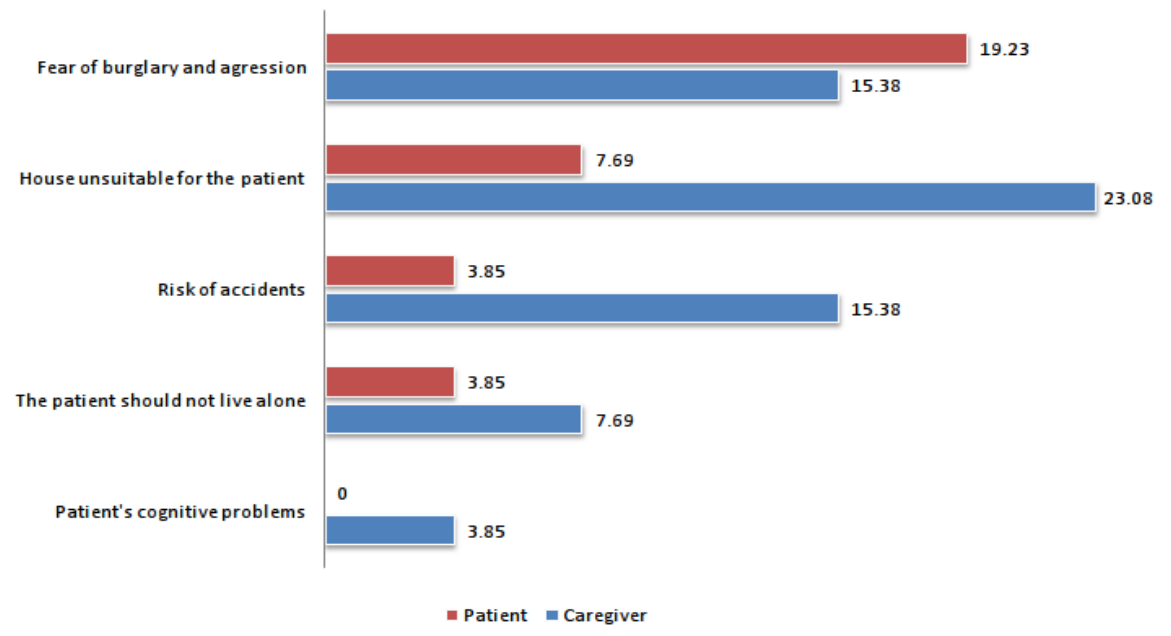

Fig. 1. Causes of patient's insecurity within the house

From this study, we observe a strong divergence in opinion between the patient and the caregiver. The caregivers tend to be more worried about the elders' condition, whereas the elders themselves may deny it, and develop social complications.

Fig. 2 shows the caregivers' opinions about healthcare services for elderly people. As we can see, $1 \%$ of them are concerned about health monitoring, while $29 \%$ want to support the elderly people for living independently, and $29 \%$ mention the improvements in the patient's quality of life. $18 \%$ of the caregivers acknowledge that

${ }^{1}$ Association Nationale des Retraités de La Poste et de France Télécom (ANR) 
these services maintain a social connection for the elders (Fig. 1 has shown the importance of it, as patients may have social inabilities). Finally, $21 \%$ of the family caregivers say that assistive services are also a support for the family, giving a glimpse of the difficult condition of the family caregivers who support the patients in their daily life.

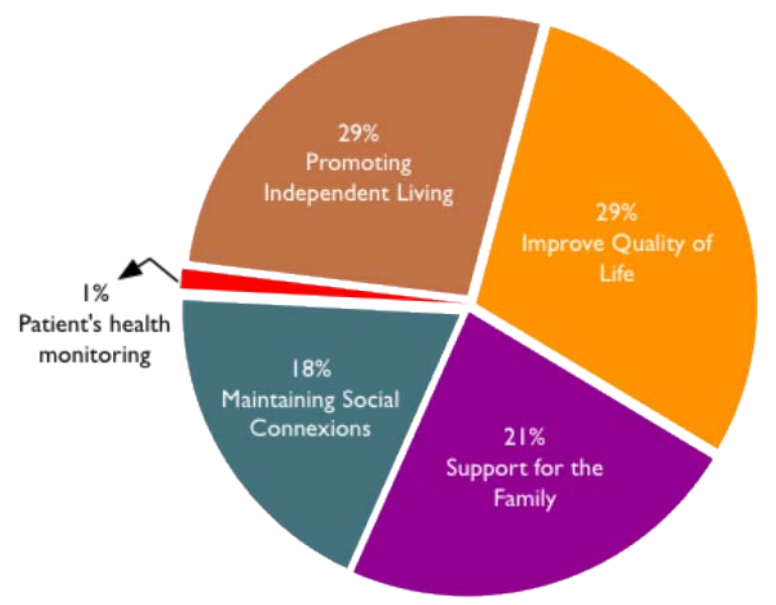

Fig. 2. Families' expectations about assistive services

As we can see from Fig. 2, the caregivers tend to be far more concerned by the quality of life and the autonomy of the elderly people, rather than by their medical condition.

\subsection{System design hardware \& software}

Our main approach for an easy adoption of an ambient assistive living solution, is to limit both the number of devices to be deployed, and the types of sensors to be used. The goal is to provide a smart home in the box approach that is easy to install on site and maintain remotely in order to allow a large-scale deployment in several homes while leveraging a server based software architecture able to instantiate each home and analyze the data coming from its deployed sensors independently. Fig. 3 illustrates a typical home environment and its associated sensors. The idea is to deploy low-cost and non-intrusive sensors (motion sensors, contact sensors) with an internet connected gateway in each home. 


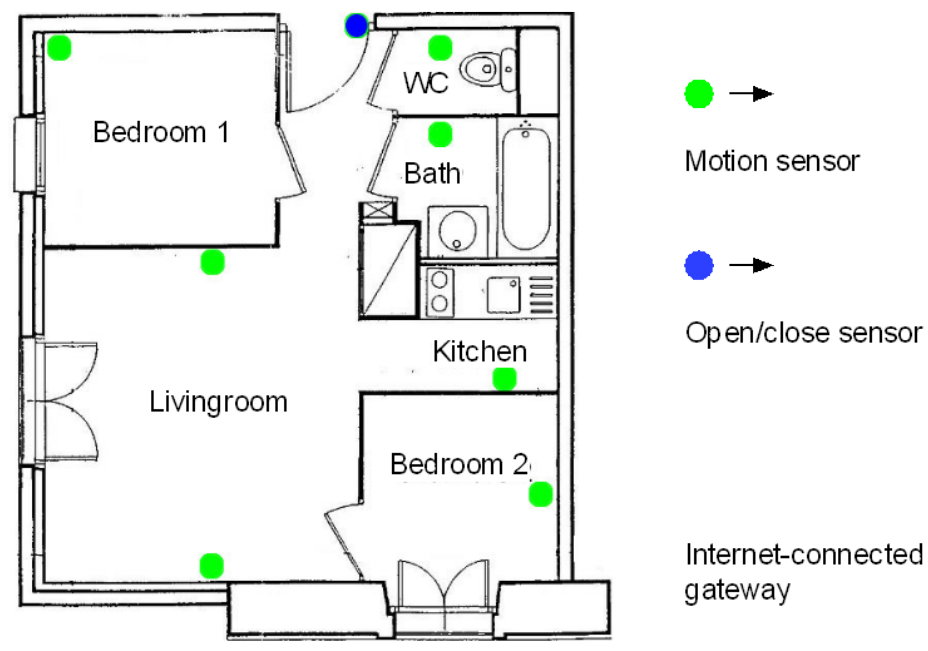

Fig. 3. Smart home is a box setup for activities recognition

On the server side, a framework is in charge of processing events sent by each home gateway and providing assistive services [6]. Our software framework is based on the OSGi (Open Service Gateway initiative) modular principle. This allows decomposing the platform into several modules, having each its specific functionality, and all communicating with each others. These modules are responsible of sensors' events reception, reasoning, taking decisions about users' situations, and providing the assistive services. A semantic model is used by the platform to represent the environment and the end-user profile.

The platform's OSGi modules are identical for each deployed house and the abstract semantic model is instantiated with information concerning each new house. Therefore, on the server side, a new instance of our framework is created and launched after the deployment of our system (sensors and gateway) in a new house and the semantic model is instantiated with the new user profile (name, address, disease, etc), as well as the description of the house and the deployed sensors characteristics (type, code, possible events, localization, etc). Fig. 4 represents the architecture of the framework developed on the server side. 


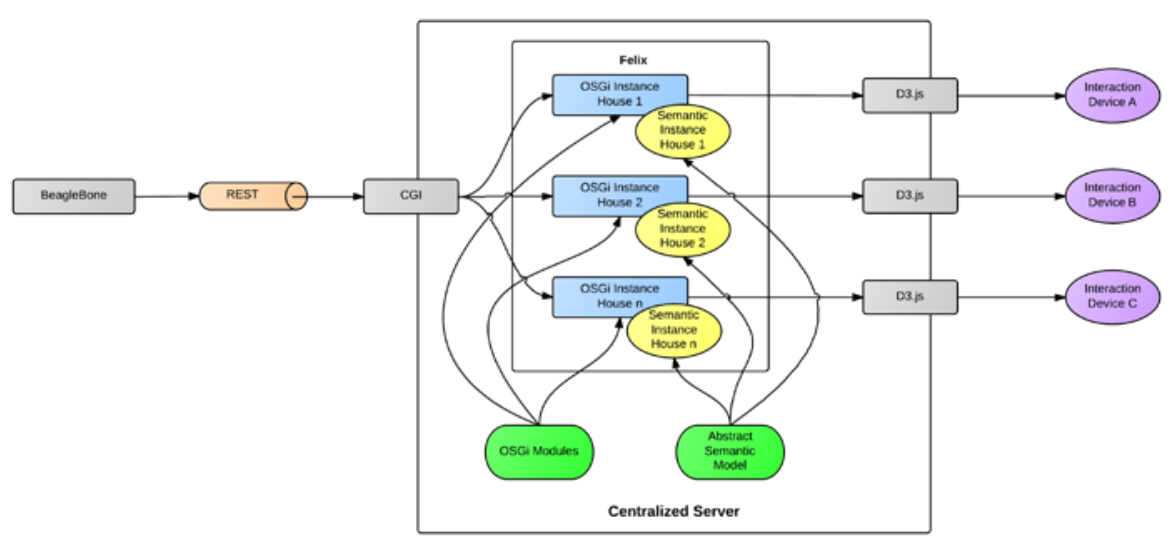

Fig. 4. Server based Software architecture

The gateway (BeagleBone Black ${ }^{2}$ ) of each house sends events received from the sensors deployed to the central server (hosted by CNRS LIRMM Lab. in Montpellier city in France). The CGI (Common Gateway Interface) on the server receives these events and routes them to the appropriate OSGi instance. After reasoning and making decisions, assistive services are provided to the end-users (patients or caregivers) on different interaction devices using the D3.js (Data-Driven Documents) library.

\section{Results}

The goal of this experimentation was to confirm the feasibility of reasoning in an AAL solution based on a stripped-down hardware deployment. This means that we must demonstrate that valuable knowledge can be extracted about an elderly person's lifestyle from coarse sensor data. Moreover, we must verify that the scalability of the incurred processing remains within an economical level, where an economy of scale is possible with one server providing enough processing power to cater for hundreds of houses.

Multiple assistive services can be provided for the end-users. These services are based on the patients' locations and activities inferred by our platform deployed on the centralized server. Fig. 5 represents a Real-time visualization of a patient's activities during the day.

\footnotetext{
${ }^{2}$ beagleboard.org/Products/BeagleBone+Black
} 


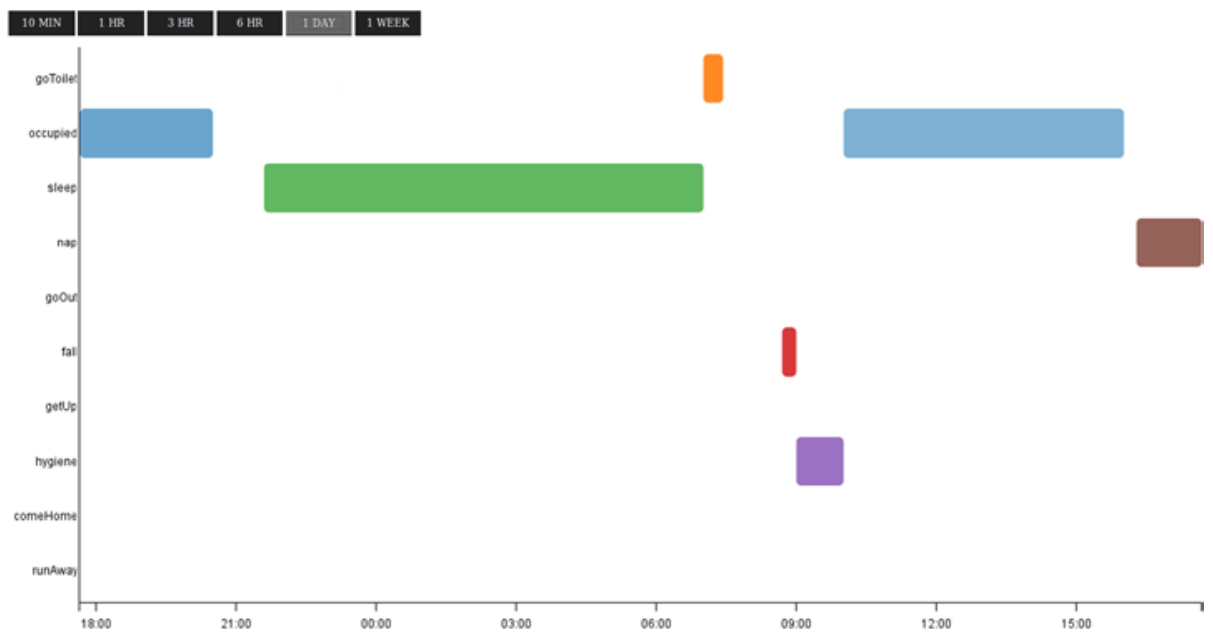

Fig. 5. Real time visualization of ADL

Relying on our conducted survey, we have identified several assistive services which are requested by the end-users and that can be provided based on the inferred information from our platform. Table 1 illustrates some of the assistive services that can be provided.

Table 1. Assistive services deduced from the conducted survey

\begin{tabular}{ll}
\hline End users expectations & Assistive services \\
\hline Improve Quality of Life & $\begin{array}{l}\text { Serious games for memory stimulation } \\
\text { Wandering at night alert }\end{array}$ \\
Promoting Independent Living & $\begin{array}{l}\text { Meals time reminders } \\
\text { Medication agenda }\end{array}$ \\
Support for the Family & $\begin{array}{l}\text { Elderly ADL visualization } \\
\text { Emergency calls in critical situations }\end{array}$ \\
Maintaining Social Connexions & Video conferences with families and friends \\
\hline
\end{tabular}

\section{Discussion}

Several technical issues have emerged from deploying technological systems in real living spaces. To perform the validation, these issues had to be dealt with, which is often considered as a "waste of time" by researchers and engineers developing systems in their lab. However, this experience allowed us to learn a lot about the targeted users and stakeholders in general, and it provides us with essential and extremely valuable knowledge related to bringing value out of our research work and 
making an impact in society. This knowledge, collected through an extensive survey, is mainly related to the feedback received from the stakeholders, the acceptance of the solutions, their ease of deployment and maintenance, usage issues, etc. Even though such deployments felt like a burden at some point in time, we can only recommend to researchers in our field to get out of the lab, deploy their solutions, and include stakeholders early in the research work.

After deploying in four bedrooms in a nursing home in Singapore [7] and three individual homes in France [8], we have improved the system along two aspects, on one hand, to simplify the hardware architecture by limiting drastically the number of devices; and on the other hand, to design a server-based framework able to instantiate each deployed site independently in a scalable manner. Experimentation within living labs in Grenoble (France) and Starhome (Singapore) provided promising results. Our next target is to deploy 10 individual homes and one nursing home in France within the Quality of Life Chair.

\section{Acknowledgements}

This project is funded under Quality of Life Chair of Institut Mines Telecom and supported by Mutuelle Generale and REUNICA.

\section{References}

1. Orwat, C., Graefe, A., Faulwasser, T.: Towards pervasive computing in health care-A literature review. BMC Medical Informatics and Decision Making journal, vol.8, p. 26. Biomedcentral (2008)

2. Bardram, J., Hansen, T., Mogensen, M., Soegaard, M.: Experiences from real-world deployment of context-aware technologies in a hospital environment. UbiComp 2006: Ubiquitous Computing. pp. 369-386 (2006)

3. Routhier, S.: Aging health and aging need. in ICOST 2011 Summer School Talks (2011)

4. Kausler, D.H.: Learning and memory in normal aging. Academic Press (1994)

5. Mokhtari, M., Aloulou, H., Tiberghien, T., Biswas, J., Racoceanu, D., Yap, P: New trends to support independence in persons with mild dementia - a mini-review. Gerontology, vol. 58, no 6, pp. 554-563. KARGER (2012)

6. Aloulou, H., Mokhtari, M., Tiberghien, T., Biswas, J., Yap, P.: An Adaptable and Flexible Framework for Assistive Living of Cognitively Impaired People. IEEE Journal of Biomedical and Health Informatics (J-BHI), vol. 18, no 1, pp. 353-360. IEEE (2014)

7. Aloulou, H., Mokhtari, M., Tiberghien, T., Biswas, J., Phua, C., Lin, J.H.K., Yap, P.: Deployment of assistive living technology in a nursing home environment: methods and lessons learned. BMC medical informatics and decision making journal, vol. 13, no 1, p. 42. Biomedcentral (2013)

8. Tiberghien, T., Strategies for Context Reasoning in Assistive Livings for the Elderly. PhD thesis. Institut SudParis (2013) 


\section{Consent to Publish}

\section{Lecture Notes in Computer Science}

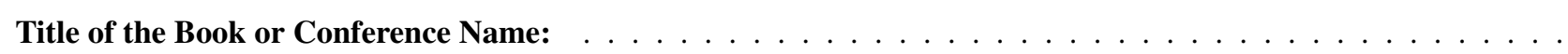
Volume Editor(s): Cathy. Bodine, Sumi.Helal, Tao. Gu and Mounir.Mokhtari.

Title of the Contribution: Measuring the Impact of ICTs on the Quality of Life of Ageing People with Mild Dementia

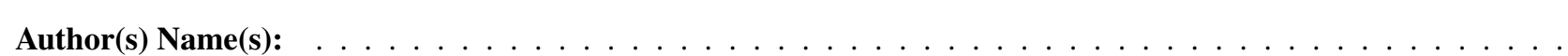

Corresponding Author's Name, Address, Affiliation and Email: Hamdi. Aloulou, . . . . . . . . . . . . . . . .LIRMM, 95 rue de la Galera, 34090 Montpellier., France .Institut.Mines-Télécom, hamdi,aloulou@mines-telecom.fr.

When Author is more than one person the expression "Author" as used in this agreement will apply collectively unless otherwise indicated.

\section{$\S 1$ Rights Granted}

Author hereby grants and assigns to Springer International Publishing AG, Cham (hereinafter called Springer) the exclusive, sole, permanent, world-wide, transferable, sub-licensable and unlimited right to reproduce, publish, distribute, transmit, make available or otherwise communicate to the public, translate, publicly perform, archive, store, lease or lend and sell the Contribution or parts thereof individually or together with other works in any language, in all revisions and versions (including soft cover, book club and collected editions, anthologies, advance printing, reprints or print to order, microfilm editions, audiograms and videograms), in all forms and media of expression including in electronic form (including offline and online use, push or pull technologies, use in databases and networks for display, print and storing on any and all stationary or portable end-user devices, e.g. text readers, audio, video or interactive devices, and for use in multimedia or interactive versions as well as for the display or transmission of the Contribution or parts thereof in data networks or seach engines), in whole, in part or in abridged form, in each case as now known or developed in the future, including the right to grant further time-limited or permanent rights. For the purposes of use in electronic forms, Springer may adjust the Contribution to the respective form of use and include links or otherwise combine it with other works. For the avoidance of doubt, Springer has the right to permit others to use individual illustrations and may use the Contribution for advertising purposes.

The copyright of the Contribution will be held in the name of Springer. Springer may take, either in its own name or in that of copyright holder, any necessary steps to protect these rights against infringement by third parties. It will have the copyright notice inserted into all editions of the Contribution according to the provisions of the Universal Copyright Convention (UCC) and dutifully take care of all formalities in this connection in the name of the copyright holder.

\section{$\S 2$ Regulations for Authors under Special Copyright Law}

The parties acknowledge that there may be no basis for claim of copyright in the United States to a Contribution prepared by an officer or employee of the United States government as part of that person's official duties. If the Contribution was performed under a United States government contract, but Author is not a United States government employee, Springer grants the United States government royalty-free permission to reproduce all or part of the Contribution and to authorize others to do so for United States government purposes.

If the Contribution was prepared or published by or under the direction or control of Her Majesty (i.e., the constitutional monarch of the Commonwealth realm) or any Crown government department, the copyright in the Contribution shall, subject to any agreement with Author, belong to Her Majesty.

If the Contribution was created by an employee of the European Union or the European Atomic Energy Community (EU/Euratom) in the performance of their duties, the regulation 31/EEC, 11/EAEC (Staff Regulations) applies, and copyright in the Contribution shall, subject to the Publication Framework Agreement (EC Plug), belong to the European Union or the European Atomic Energy Community.

If Author is an officer or employee of the United States government, of the Crown, or of EU/Euratom, reference will be made to this status on the signature page.

\section{§3 Rights Retained by Author}

Author retains, in addition to uses permitted by law, the right to communicate the content of the Contribution to other scientists, to share the Contribution with them in manuscript form, to perform or present the Contribution or to use the content for non-commercial internal and educational purposes, provided the Springer publication is mentioned as the 
original source of publication in any printed or electronic materials. Author retains the right to republish the Contribution in any collection consisting solely of Author's own works without charge subject to ensuring that the publication by Springer is properly credited and that the relevant copyright notice is repeated verbatim.

Author may self-archive an author-created version of his/her Contribution on his/her own website and/or the repository of Author's department or faculty. Author may also deposit this version on his/her funder's or funder's designated repository at the funder's request or as a result of a legal obligation. He/she may not use the publisher's PDF version, which is posted on SpringerLink and other Springer websites, for the purpose of self-archiving or deposit. Furthermore, Author may only post his/her own version, provided acknowledgment is given to the original source of publication and a link is inserted to the published article on Springer's website. The link must be provided by inserting the DOI number of the article in the following sentence: "The final publication is available at Springer via http://dx.doi.org/[insert DOI]". The DOI (Digital Object Identifier) can be found at the bottom of the first page of the published paper.

Prior versions of the Contribution published on non-commercial pre-print servers like ArXiv/CoRR and HAL can remain on these servers and/or can be updated with Author's accepted version. The final published version (in pdf or html/xml format) cannot be used for this purpose. Acknowledgment needs to be given to the final publication and a link must be inserted to the published Contribution on Springer's website, by inserting the DOI number of the article in the following sentence: "The final publication is available at Springer via http://dx.doi.org/[insert DOI]".

Author retains the right to use his/her Contribution for his/her further scientific career by including the final published paper in his/her dissertation or doctoral thesis provided acknowledgment is given to the original source of publication. Author also retains the right to use, without having to pay a fee and without having to inform the publisher, parts of the Contribution (e.g. illustrations) for inclusion in future work, and to publish a substantially revised version (at least $30 \%$ new content) elsewhere, provided that the original Springer Contribution is properly cited.

\section{$\$ 4$ Warranties}

Author warrants that the Contribution is original except for such excerpts from copyrighted works (including illustrations, tables, animations and text quotations) as may be included with the permission of the copyright holder thereof, in which case(s) Author is required to obtain written permission to the extent necessary and to indicate the precise sources of the excerpts in the manuscript. Author is also requested to store the signed permission forms and to make them available to Springer if required.

Author warrants that he/she is entitled to grant the rights in accordance with Clause 1 "Rights Granted", that he/she has not assigned such rights to third parties, that the Contribution has not heretofore been published in whole or in part, that the Contribution contains no libelous statements and does not infringe on any copyright, trademark, patent, statutory right or proprietary right of others, including rights obtained through licenses; and that Author will indemnify Springer against any costs, expenses or damages for which Springer may become liable as a result of any breach of this warranty.

\section{$\$ 5$ Delivery of the Work and Publication}

Author agrees to deliver to the responsible Volume Editor (for conferences, usually one of the Program Chairs), on a date to be agreed upon, the manuscript created according to the Springer Instructions for Authors. Springer will undertake the reproduction and distribution of the Contribution at its own expense and risk. After submission of the Consent to Publish form Signed by the Corresponding Author, changes of authorship, or in the order of the authors listed, will not be accepted by Springer.

\section{$\S 6$ Author's Discount}

Author is entitled to purchase for his/her personal use (directly from Springer) the Work or other books published by Springer at a discount of $331 / 3 \%$ off the list price as long as there is a contractual arrangement between Author and Springer and subject to applicable book price regulation. Resale of such copies or of free copies is not permitted.

\section{\$ 7 Governing Law and Jurisdiction}

This agreement shall be governed by, and shall be construed in accordance with, the laws of Switzerland. The courts of Zug, Switzerland shall have the exclusive jurisdiction.

Corresponding Author signs for and accepts responsibility for releasing this material on behalf of any and all Co-authors.

Signature of Corresponding Author:

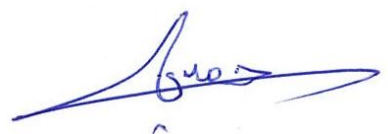

Date:

07-05-2014

I'm an employee of the US Government and transfer the rights to the extent transferable

(Title $17 \S 105$ U.S.C. applies)

I'm an employee of the Crown and copyright on the Contribution belongs to Her Majesty

I'm an employee of the EU or Euratom and copyright on the Contribution belongs to EU or Euratom 